\title{
Neural Network Partitioning by NO and cGMP
}

\author{
Nathaniel L. Scholz, ${ }^{1}$ Jan de Vente, ${ }^{2}$ James W. Truman, ${ }^{1}$ and Katherine Graubard ${ }^{1}$ \\ 1 University of Washington, Department of Zoology, Seattle, Washington 98195-1800, and 2University of Maastricht, \\ Department of Psychiatry and Neuropsychology, 6200 MD Maastricht, The Netherlands
}

The stomatogastric ganglion (STG) of the crab Cancer productus contains $\sim 30$ neurons arrayed into two different networks (gastric mill and pyloric), each of which produces a distinct motor pattern in vitro. Here we show that the functional division of the STG into these two networks requires intact NO-cGMP signaling. Multiple nitric oxide synthase (NOS)-like proteins are expressed in the stomatogastric nervous system, and NO appears to be released as an orthograde transmitter from descending inputs to the STG. The receptor of NO, a soluble guanylate cyclase (sGC), is expressed in a subset of neurons in both motor networks. When NO diffusion or SGC activation are blocked within the ganglion, the two networks combine into a single conjoint circuit. The gastric mill motor rhythm breaks down, and several gastric neurons pattern switch and begin firing in pyloric time. The functional reorganization of the STG is both rapid and reversible, and the gastric mill motor rhythm is restored when the ganglion is returned to normal saline. Finally, pharmacological manipulations of the NO-cGMP pathway are ineffective when descending modulatory inputs to the STG are blocked. This suggests that the NO-cGMP pathway may interact with other biochemical cascades to partition rhythmic motor output from the ganglion.

Key words: NO; nitric oxide; cGMP; guanylate cyclase; stomatogastric; plasticity; crustacean; central pattern generator; cross talk
Nitric oxide (NO) serves many different functions in the nervous systems of vertebrates (Garthwaite and Boulton, 1995; Denninger and Marletta, 1999) and invertebrates (Jacklet, 1997; Scholz and Truman, 2000). Because NO is a highly mobile and membranepermeant gas, it has the potential to synchronize the activity of neurons that share a common diffusional space (Gally et al., 1990). This may be particularly important for oscillatory neural circuits. For example, NO is involved in the activation or modulation of thalamocortical (Pape and Mager, 1992) and olfactory networks (Gelperin et al., 2000), as well as rhythmic motor networks associated with feeding (Elphick et al., 1995), respiration (Hedrick and Morales, 1999), and locomotion (McLean and Sillar, 2000).

The rhythmic circuits of the crustacean stomatogastric ganglion (STG) are particularly well suited for studying specific mechanisms of NO-mediated neuromodulation. The STG contains $\sim 30$ neurons arrayed into the gastric mill and pyloric motor circuits. These two networks generate very different motor patterns (Heinzel et al., 1993). Gastric mill neurons fire bursts of action potentials that last for several seconds and cycle at a period of 5-20 sec. These relatively long bouts of activity drive the grinding movements of the medial and paired lateral teeth of the gastric mill. The pyloric circuit, which underlies the sorting and filtering movements in the pyloric chamber, produces a distinct triphasic

\footnotetext{
Received Sept. 18, 2000; revised Nov. 29, 2000; accepted Dec. 5, 2000.

This work was supported by a National Institutes of Health predoctoral traineeship to N.L.S. and National Institutes of Health Grants NS13079 to J.W.T. and NS15697 to K.G. We thank Jana Labenia for the anti-citrulline staining and technical assistance throughout all phases of this work. We also thank Sarah Gibbs for comments on this manuscript, Wes Grueber for purifying the citrulline antibody, and Ian Kasman for neurobiotin backfills.

Correspondence should be addressed to Dr. Nat Scholz, Environmental Conservation Division, Northwest Fisheries Science Center, 2725 Montlake Boulevard East, Seattle, WA 98112. E-mail: Nathaniel.Scholz@noaa.gov.

Dr. Scholz's present address: Northwest Fisheries Science Center, 2725 Montlake Boulevard East, Seattle, WA 98112.

Copyright (C) 2001 Society for Neuroscience $\quad 0270-6474 / 01 / 211610-09 \$ 15.00 / 0$
}

output with a short cycle period of 1-2 sec. Importantly, some motorneurons that innervate gastric muscles can switch to fire in pyloric time, and vice versa (Weimann et al., 1991; Weimann and Marder, 1994). Consequently, STG networks are not fixed, but instead are dynamically assembled from a pool of synaptically coupled cells.

Parallel modulatory inputs from circulating neurohormones, sensory afferents, and descending projection neurons (HarrisWarrick et al., 1992; Marder et al., 1994) play an important role in the specification of the gastric mill and pyloric networks (Harris-Warrick et al., 1997). For example, both motor patterns are significantly diminished or abolished when descending inputs to the ganglion are blocked (Weimann et al., 1997). Conversely, bath application of modulatory transmitters to the STG, including serotonin (Katz and Harris-Warrick, 1989), proctolin (Marder et al., 1986; Heinzel and Selverston, 1988), cholecystokinin-like peptides (Turrigiano and Selverston, 1990), and FLRFamides (Weimann et al., 1993) elicit the simultaneous production of the two different rhythms. Moreover, the activation of sensory inputs (Katz and Harris-Warrick, 1989) and descending projection neurons (Dickinson et al., 1988; Coleman and Nusbaum, 1994; Blitz et al., 1999) can modify the functional properties of both networks. These inputs also modify synaptic interactions between gastric mill and pyloric neurons (Katz and Harris-Warrick, 1991; Bartos and Nusbaum, 1997; Nadim et al., 1998; Bartos et al., 1999). Therefore, neuromodulatory inputs initiate both motor patterns and coordinate interactions between the two active networks.

Here we show that nitric oxide (NO) is a modulatory neurotransmitter in the STG of the crab Cancer productus. Moreover, we identify a subset of neurons in the gastric mill and pyloric motor networks that express the receptor of NO, an NO-sensitive soluble guanylate cyclase (sGC). These neurons produce cGMP in response to NO. In spontaneously active preparations of the in 
vitro STG, the two motor patterns collapse into a single conjoint rhythm when the NO-cGMP pathway is blocked. However, NOmediated signaling is ineffective in the absence of parallel neuromodulatory inputs to the ganglion. Overall, these findings suggest that neural network partitioning in the STG may arise, in part, from interactions between cGMP and other transmitterevoked biochemical cascades.

\section{MATERIALS AND METHODS}

Animals. Adult male rock crabs (Cancer productus) were hand-collected from Puget Sound and maintained without food in seawater aquaria at $12^{\circ} \mathrm{C}$. Animals were anesthetized by chilling on ice, and the stomatogastric nervous system (STNS) was dissected as described by Mulloney and Selverston (1974). Briefly, the foregut was removed, cut ventrally, and pinned with the dorsal side up in a dish containing cold crab saline (in mM: $440 \mathrm{NaCl}, 11 \mathrm{KCl}, 13 \mathrm{CaCl}_{2}, 26 \mathrm{MgCl}_{2}$, and 10 HEPES, pH 7.4, with $\mathrm{NaOH}$ ). The STNS was prepared as previously described for immunocytochemistry (Scholz et al., 1996) and electrophysiological recordings (Baldwin and Graubard, 1995). Brain and muscle tissues were dissected in cold saline and transferred to glass vials.

Western blotting. Proteins were isolated from gastric mill (GM) muscle (1a and b), brain, and STNS by homogenization in $250 \mathrm{~mm}$ Tris- $\mathrm{HCl}, \mathrm{pH}$ $6.8,8 \%$ SDS, $40 \%$ glycerol, $0.01 \%$ bromophenol blue, and $20 \%$ B-2 mercaptoethanol. After boiling, the homogenates were centrifuged $(10,000 \times g, 6 \mathrm{~min})$, and the supernatants were frozen at $-70^{\circ} \mathrm{C}$. Proteins were separated on $8 \%$ SDS-PAGE and electrotransferred onto Protran nitrocellulose (Schleicher and Schuell, Keene, NH) overnight at $30 \mathrm{~V}$. Membranes were blocked in $50 \mathrm{~mm}$ Tris-HCl, pH 7.8, $150 \mathrm{~mm} \mathrm{NaCl}, 1$ mM EDTA, and $0.1 \%$ Tween 20 (TBST) containing 5\% dried nonfat milk and 5\% bovine serum albumin for $2 \mathrm{hr}$. Membranes were then incubated for $2 \mathrm{hr}$ in rabbit anti-Universal NOS (uNOS; Affinity Bioreagents, Golden, CO) at 1:1000 and mouse anti-actin (Sigma, St. Louis, MO) at 1:500 in TBST and 5\% dried nonfat milk. Actin staining was included as a control for loading. After a wash, membranes were incubated with horseradish peroxidase-conjugated donkey anti-mouse (1: $1000)$ and goat anti-rabbit (1:1000) secondary antibodies (both from Jackson ImmunoResearch, West Grove, PA). Detection was enhanced by chemiluminescence (ECL) using a kit from Amersham (Arlington Heights, IL).

Whole-mount immunocytochemistry for uNOS, citrulline, and cGMP. The procedure and controls for uNOS and cGMP immunocytochemistry have been described previously (Scholz et al., 1996; de Vente and Steinbusch, 1997). For cGMP staining, in vitro nervous systems were first stimulated with $10 \mathrm{~mm}$ sodium nitroprusside (SNP) and $0.5 \mathrm{~mm}$ 3-isobutyl-1-methylxanthine (IBMX) for $15 \mathrm{~min}$. and fixed overnight at $4^{\circ} \mathrm{C}$ in $4 \%$ paraformaldehyde (Electron Microscopy Sciences, Fort Washington, PA) in $0.1 \mathrm{~m}$ PBS. For uNOS and cGMP labeling, tissues were washed in PBS containing 0.3\% Triton X-100 (PBST; Sigma) and incubated overnight with either a rabbit anti-uNOS antiserum (1:200) or a rabbit anti-cGMP antiserum (1:1000) in PBST and 5\% normal goat serum. Primary antisera were occasionally reused (one to three experiments total). For citrulline staining, tissues were fixed in $4 \%$ glutaraldehyde (Electron Microscopy Sciences), followed by a 20 min reduction in PBS containing $0.5 \%$ sodium borohydride and $0.2 \%$ sodium metabisulfite. This was followed by several washes in $0.2 \%$ sodium metabisulfite PBS. The tissues were rinsed in PBST and then incubated overnight in a rabbit anti-citrulline antiserum (1:200), generously provided by Mikael J. L. Eliasson and Solomon Snyder (Johns Hopkins University, Baltimore, MD). For all three antibodies, tissues were incubated overnight in a Cy5-conjugated donkey anti-rabbit secondary antibody (1:1000; Jackson ImmunoResearch) or, for double-label experiments (see below), a Texas Red-conjugated goat anti-rabbit secondary (1:400; Jackson). Secondary antisera were presorbed overnight against crab brain (paraformaldehyde-fixed and washed) in 5\% normal goat serum to reduce nonspecific binding. As a control, tissues were also processed in the absence of primary antisera. Labeled nervous systems were arranged on poly-L-lysine-coated coverslips, dehydrated in alcohol, cleared in xylene, and mounted in DPX (Fluka, Ronkonkoma, NY).

Confocal imaging and analysis. Fluorescently labeled nervous systems (anti-citrulline and anti-cGMP) were imaged with a Bio-Rad (Hercules, CA) MRC 600 laser-scanning confocal microscope as described previously (Scholz et al., 1998). For double labels, the STG was imaged using $\mathrm{K} 1 / \mathrm{K} 2$ filter blocks provided by the vendor. Optical sections were ac-

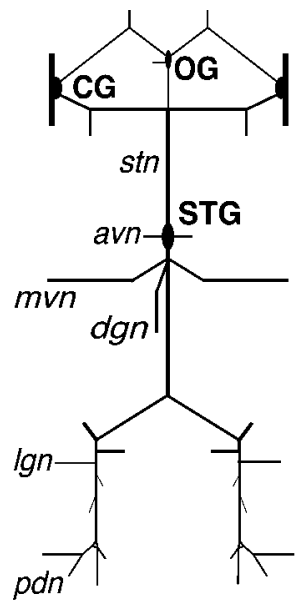

Figure 1. Schematic diagram of the in vitro crab STNS. Anterior is up. avn, Anterior ventricular nerve; $C G$, commissural ganglion; $d g n$, dorsal gastric nerve; $\lg n$, lateral gastric nerve; $m v n$, median ventricular nerve; $O G$, esophageal ganglion; $p d n$, pyloric dilator nerve; stn, stomatogastric nerve.

quired at 1,2, or $3 \mu \mathrm{m}$ intervals. Each figure represents multiple optical sections that were combined into a projection using the brightest point procedure in NIH Image (public domain software for Macintosh, version 1.61, developed at the United States National Institutes of Health and available at http://rsb.info.nih.gov/nih-image/). Unless otherwise indicated, each projection spans the entire thickness of the STG. Montages were assembled using Adobe Photoshop 3.0.1. Labels were added in Deneba's Canvas 5.0.

Electrophysiological recordings. Electrophysiological experiments were performed on isolated preparations of the STNS (Fig. 1). The commisural ganglia (CGs), esophageal ganglion (OG), STG, and attached nerves were pinned out on a Sylgard-coated dish and bathed in crab physiological saline $\left(11-13^{\circ} \mathrm{C}\right)$. The connections between the anterior ganglia and the STG were intact in all preparations. The STG was desheathed, and a Vaseline well was placed around the ganglion. All pharmacological agents were delivered exclusively to the STG via bath application. For sucrose block experiments, a Vaseline well was used to isolate the anterior ganglia from the STG. The physiological saline surrounding anterior ganglia was then replaced with an isotonic sucrose solution.

Intracellular recordings from STG neurons were made with an Axoclamp 2A (Axon Instruments, Foster City, CA) using standard techniques (Baldwin and Graubard, 1995). Cell bodies in the ganglion were impaled with microelectrodes made from thin-walled capillary glass (A-M Systems, Carlsborg, WA) filled with $3 \mathrm{~m} \mathrm{KCl}$. Usual resistances ranged from 10 to $20 \mathrm{M} \Omega$. Motor output from the STG was monitored extracellularly with the use of suction electrodes. Extracellular signals were amplified with a differential amplifier (A-M Systems). Intracellular and extracellular recordings were digitized using a 1401 Plus analog-todigital converter (Cambridge Electronic Designs, Cambridge, UK) and analyzed using Spike 2 (version 2.01, Cambridge Electronic Designs).

Identification of NO-sensitive STG neurons. Soluble guanylate cyclase (sGC) is a critical component of NO-mediated signaling (Denninger and Marletta, 1999; Zhao et al., 1999). NO-activated sGC catalyzes the synthesis of cGMP from GTP. Consequently, NO-sensitive neurons are defined as cells that show a detectable increase in cGMP immunoreactivity after exposure to an NO donor (SNP) and a phosphodiesterase inhibitor (IBMX) (Truman et al., 1996; Gibbs and Truman, 1998; Scholz et al., 1996, 1998). To determine which STG neurons are targets for NO (as revealed by cGMP production after sGC activation) we filled identified neurons with Lucifer Yellow and processed the ganglion for NOinduced cGMP immunocytochemistry. Neuron identification was based on: (1) appropriate intracellular waveform; (2) matched spikes in the intracellular soma recording and appropriate extracellular nerve recording; and (3) excitation or inhibition of spiking in the appropriate nerve after somatic injections of positive or negative current (usually 1-2 nA), respectively. Up to eight identified somata per experiment were impaled with an electrode containing Lucifer Yellow (3-5\%) and $1 \mathrm{M} \mathrm{LiCl}$. Dye was injected iontophoretically for 20-40 min using $1 \mathrm{nA}$ of negative current. The STG was removed from the dish, stimulated with $10 \mathrm{~mm}$ 
SNP and $0.5 \mathrm{~mm}$ IBMX for $15 \mathrm{~min}$, and fixed overnight in $4 \%$ paraformaldehyde. The STG was then processed for anti-cGMP immunocytochemistry as described above. Each ganglion was confocally imaged, and NO-sensitive (cGMP-containing) neurons were identified by color merging the projected images of cGMP labeling and Lucifer Yellow cell fills in Adobe Photoshop 3.0.1.

To identify NO-sensitive neurons in the STG that project anteriorly in the stn, the nerve was cut anterior to the STG and backfilled with neurobiotin (Vector Laboratories, Burlingame, CA). The free end of the stn was placed in a Vaseline well containing neurobiotin $(5 \%$ in distilled water) for $2 \mathrm{hr}$ at $4^{\circ} \mathrm{C}$. The ganglion was then stimulated with SNPIBMX, processed for cGMP immunocytochemistry, and imaged as described above. Streptavidin Oregon Green 488 (1:200; Molecular Probes, Eugene, OR) was used to visualize the neurobiotin tracer.

Chemicals. SNP, IBMX, and 8-bromoguanosine 3',5'-cyclic monophosphate (8-bromo-cGMP) were obtained from Sigma, and 3-morpholinosydnonimine (SIN-1) was obtained from Biomol (Plymouth Meeting, PA). 1H-(1,2,4)oxadiazolo(4,3-a)-quinoxalin-1-one (ODQ) was purchased from Alexis (San Diego, CA). ODQ was stored at room temperature as a $100 \mathrm{~mm}$ stock in $100 \%$ DMSO, and dissolved into crab saline before each experiment ( $0.1 \%$ final DMSO concentration). Control applications of $0.1-1 \%$ DMSO alone to the STG had no effect on either cGMP immunocytochemistry or motor pattern production. 2-Phenyl-4,4,5,5-tetramethylimidazoline-1-oxyl-3-oxide (PTIO) was purchased from Calbiochem (La Jolla, CA) and stored as a $10 \mathrm{~mm}$ stock in normal crab saline at $4^{\circ} \mathrm{C}$. Lucifer Yellow was obtained from Molecular Probes. Unless otherwise noted, solutions were made up fresh at the appropriate time during each experiment. All solutions containing NO donors were used within minutes of dissolution of the donor in crab saline.

\section{RESULTS}

\section{Components of the NO-cGMP signaling pathway in the STNS}

The STNS is illustrated in Figure 1. To identify NO-synthase (NOS)-like proteins, we probed extracts from crab brain, STNS, and foregut muscle (GM1) with a polyclonal antibody raised against a conserved sequence of NOS (uNOS). It has previously been shown that the crustacean brain contains a biochemically and histochemically identifiable NOS (Johansson and Carlberg, 1994), and this tissue was included as a positive control. Western blot analyses $(n=5)$ show that crab brain contains four NOS-like proteins, the larger two of which $(\sim 135$ and $155 \mathrm{kDa})$ are also present in the STNS (Fig. 2A).

The uNOS antibody did not reliably stain neuronal structures in whole-mount preparations of the STNS (data not shown). However, in a few preparations ( $n=3$ of 9 experiments), the antibody labeled a single small somata in the STG. As an alternative approach to localizing NOS, we examined the STG for evidence of NOS enzymatic activity in the form of citrulline production. Citrulline is a byproduct of NO formation from arginine (Bredt and Snyder, 1990), and anti-citrulline immunocytochemistry has been shown to faithfully reflect NOS activity in neurons (Eliasson et al., 1997). Under basal conditions (normal physiological saline; $n=7$ ), citrulline was evident in two axons that enter the STG via the stomatogastric nerve (the stn) (Fig. 2B). Citrulline staining intensified in the descending fibers and the neuropil when the STG was desheathed and preincubated with $1 \mathrm{~mm}$ L-arginine $(n=4$; Fig. $2 C)$. Overall, this staining pattern suggests that a pair of unidentified input fibers contain an NOS.

cGMP immunocytochemistry has been used to identify neurons in the STG that contain a NO-sensitive sGC (Scholz et al., 1996). Normal physiological levels of cGMP in the ganglion are below the detection threshold for the antibody. However, bath applications of NO donors such as SNP (10 mM) cause a 10- to 20 -fold increase in cGMP content of the STG and elicit detect-
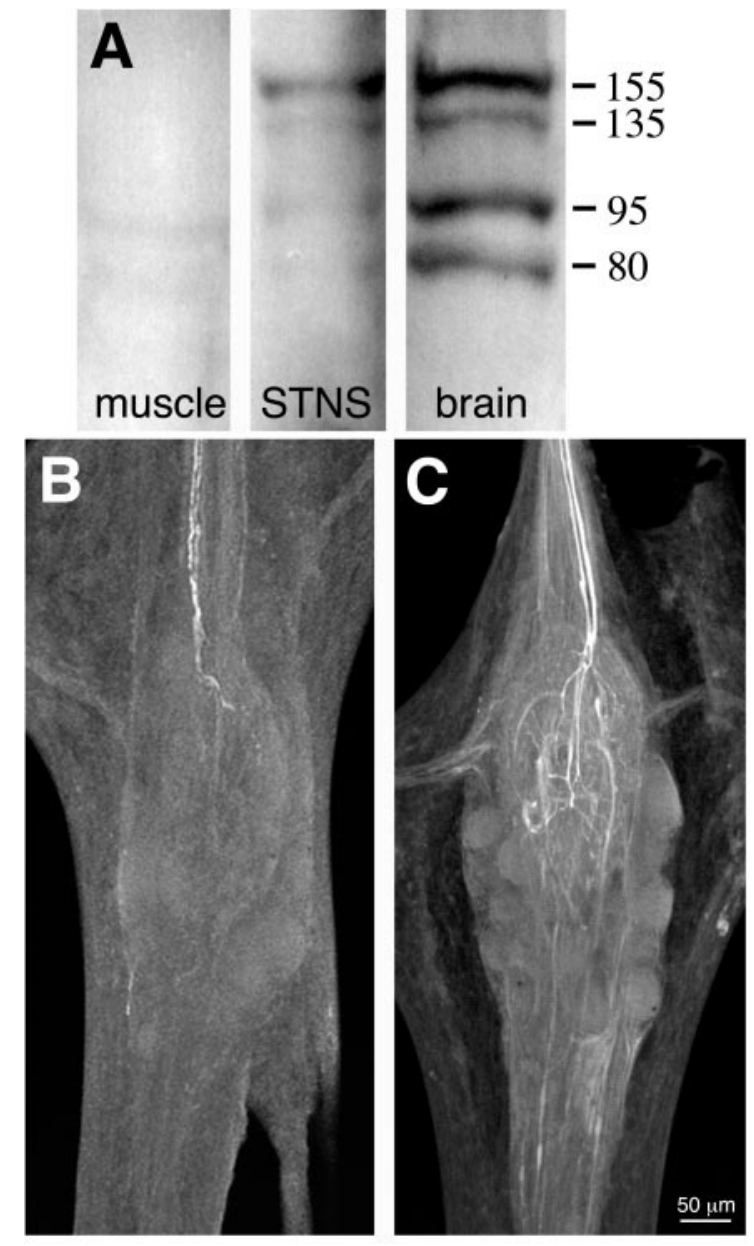

Figure 2. NOS expression and activity in the STNS. $A$, Western blot of proteins extracted from crab muscle, STNS, and brain using a polyclonal antibody raised against a conserved domain of NOS (uNOS). Molecular weights (in kilodaltons) are indicated to the right. $B, C$, Whole-mount confocal projections of stomatogastric ganglia reacted with a polyclonal antibody raised against citrulline, a byproduct of NOS enzymatic activity. Each projection is a complete image through the ganglion. $B$, Putative NOS enzymatic activity is present under basal conditions in two projection neurons that enter the STG via the $\operatorname{stn}$ (at top; $n=5$ ). Citrulline accumulation is localized exclusively to the posterior stn and the STG (data not shown). $C$, Citrulline staining in the two input fibers is enhanced when the perineural sheath is removed and the STG is preincubated for $30 \mathrm{~min}$ in $1 \mathrm{~mm}$ L-arginine $(n=3)$. Note extensive branching of citrulline-containing terminals in the central synaptic region of the ganglion (neuropil). Because the citrulline antibody cross-reacts with high concentrations of arginine in the nervous system (Eliasson et al., 1997), the faint background staining in unidentified axons may reflect arginine accumulation in these processes.

able cGMP synthesis in $\sim 13$ neurons within the ganglion $(n=14$; Fig. $3 A$; Scholz et al., 1996). Importantly, to produce these high levels of cGMP, it is necessary to block endogenous phosphodiesterase activity with IBMX. Under these conditions, most NOsensitive cells ( $\sim 9)$ showed intense cGMP immunoreactivity, whereas a few (three or four) labeled only weakly. As shown in Figure $3 B$, NO-induced cGMP production was abolished when the ganglion was pretreated with $50 \mu \mathrm{M}$ ODQ, a specific inhibitor of NO-sensitive sGC (Garthwaite et al., 1995).

The presence of citrulline-like immunoreactivity in descending inputs to the STG (Fig. 2B,C) suggests that NO may be released into the synaptic neuropil of the ganglion. To test whether the 


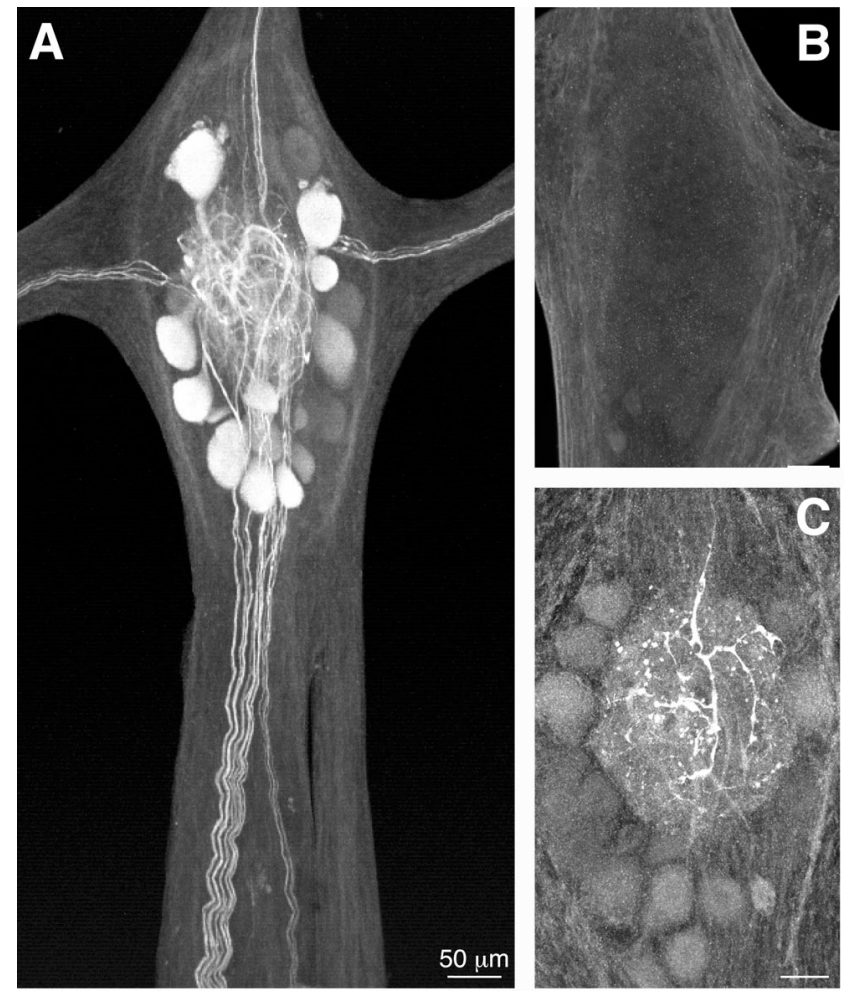

Figure 3. cGMP immunostaining in the STG. $A-C$ are whole-mount confocal projections of ganglia that have been labeled with a polyclonal antibody raised against cGMP. $A$, Bath application of NO activates cGMP synthesis in a subset of STG neurons. The in vitro ganglion was treated with an NO donor (10 $\mathrm{mm}$ SNP) and processed for cGMP immunocytochemistry $(n=10)$. As previously reported (Scholz et al., 1996), a subset $(\sim 13)$ of the $\sim 30$ neurons in the STG express an NOsensitive sGC. $B$, NO-induced cGMP accumulation is blocked when the STG is preincubated for $30 \mathrm{~min}$ in $50 \mu \mathrm{M}$ ODQ, a selective inhibitor of sGC $(n=5)$. $C$, Extracellular stimulation of the $\operatorname{stn}(1 \mathrm{msec}$ pulses delivered at $100 \mathrm{~Hz}$ for $30 \mathrm{sec}$ ) activates cGMP synthesis in the STG neuropil $(n=3)$. Note that $0.5 \mathrm{~mm}$ IBMX was added to block cGMP hydrolysis in the experiments shown in $A-C$.

stimulation of these putative NOS-containing projections could drive cGMP production in the STG to detectable levels, we bathed the ganglion in IBMX and then administered a stimulus to the $\sin (30 \mathrm{sec}$ at $100 \mathrm{~Hz})$, which elicited a strong excitation of both the gastric mill and pyloric motor rhythms (as monitored with extracellular recordings from the $d v n$ ). The STG was then immediately fixed and screened for cGMP immunoreactivity $(n=3)$. After stimulation, cGMP accumulation was detected within selected processes in the neuropil (Fig. 3C). The appearance of cGMP in the neuropil is consistent with neurons responding to a local release of NO from the descending input fibers.

To determine which STG neurons were NO-sensitive, we identified individual cells (see Materials and Methods) and filled them with Lucifer Yellow. The STG was then exposed to an NO donor and IBMX and processed for cGMP immunocytochemistry (Fig. 4). Overall, 33 STG neurons belonging to eight cell classes were characterized (Table 1). The presence or absence of cGMP immunostaining was consistent, without exception, within each cell class across all experiments. Based on the circuit composition of the congener Cancer borealis (Weimann et al., 1991), we accounted for 12 of the $13 \mathrm{NO}$-sensitive neurons in the ganglion. As shown in Table 1, most NO-sensitive neurons normally participate in the pyloric network; the three classes of cells respon-

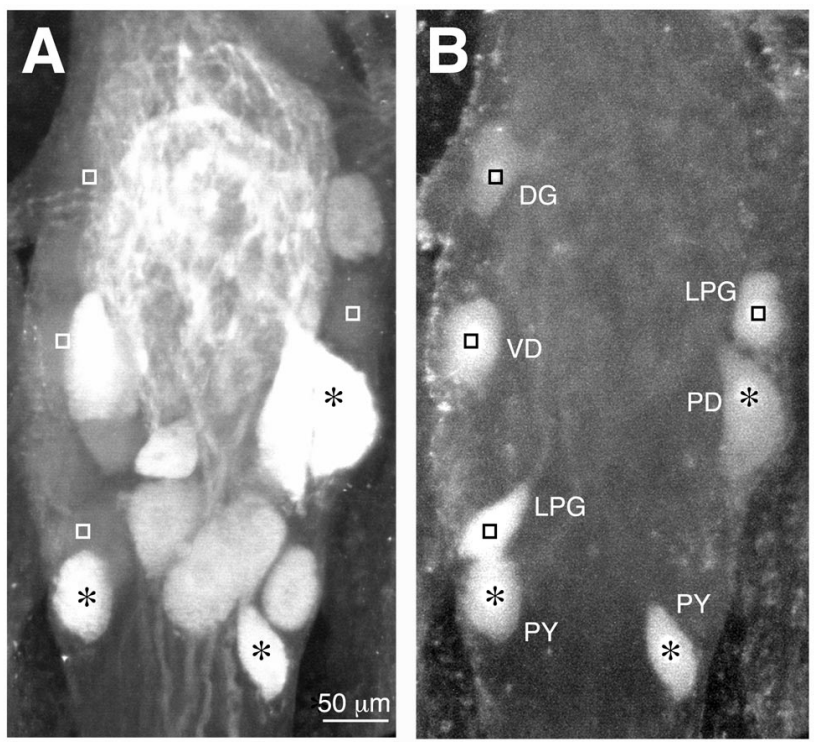

Figure 4. Identification of NO-sensitive and NO-insensitive neurons within the STG. $A$ and $B$ are side-by-side confocal projections $(\sim 75 \mu \mathrm{m}$ total thickness) from the same ganglion. $A$, NO-induced cGMP immunoreactivity in a subset of $\sim 13$ neurons. $B$, Lucifer Yellow-injected somata from seven identified cells (see Materials and Methods). The colocalization of cGMP and Lucifer Yellow was determined by merging the two projections. Neurons that have nuclei labeled with an asterisk ( $P D$ and $P Y$ ) are NO-sensitive. The remaining cells $(D G, V D$, and $L P G)$, indicated by squares, are NO-insensitive. The relative position of each asterisk and square is the same for both panels. Note that the VD neuron partially overlaps an unidentified cGMP-containing neuron in the projection. $D G$, Dorsal gastric; $L P G$, lateral posterior gastric; $P D$, pyloric dilator; $P Y$, pyloric; $V D$, ventricular dilator.

Table 1. Identification of NO-sensitive neurons in the STG.

Neurons $n$ cGMP-positive?

PD (2)

PY (5)

LP (1)

GM (4)

$\mathrm{VD}(1)$

IC (1)

DG (1)

LPG (2)

$+$

6

4

3

6

4

5

3

The number in parentheses is the number of neurons in each cell class (Weimann et al., 1991). Lucifer Yellow-injected neurons were identified as NO-sensitive or insensitive based on colocalization with cGMP immunoreactivity (see Materials and Methods). $n$ indicates the number of individual neurons identified in each cell class. Not all cell classes are represented. Abbreviations as in Figure 4 except GM, gastric mill; IC, inferior cardiac; and LP, lateral pyloric.

sible for the characteristic triphasic pyloric rhythm [lateral pyloric (LP), pyloric (PY), and pyloric dilator (PD)] are NO-sensitive. The four gastric mill (GM) neurons are also NO-sensitive. By contrast, the dorsal gastric (DG) neuron, which fires exclusively in gastric mill time, as well as the lateral posterior gastric (LPG), ventricular dilator (VD), and inferior cardiac (IC) neurons, are all NO-insensitive. We did not record from the lateral gastric (LG) or medial gastric (MG) neurons. However, it is unlikely that they are NO-sensitive because these cells project posteriorly, and the $13^{\text {th }}$ neuron sends an axon anteriorly in the stn (Fig. 5). This remaining neuron is likely to be either anterior burster $(\mathrm{AB})$ or 


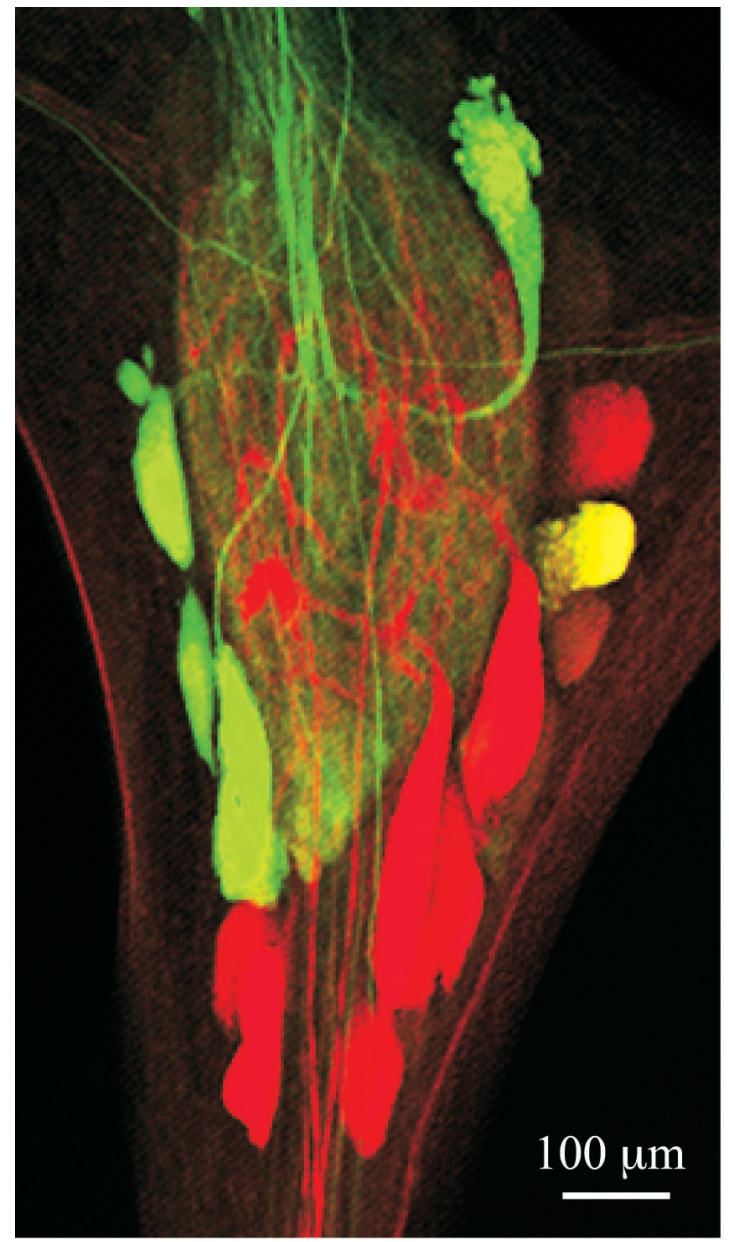

Figure 5. A single NO-sensitive STG neuron projects anteriorly in the stn (top). The stn was backfilled with neurobiotin, and the STG was stimulated with $10 \mathrm{mM} \mathrm{SNP}$ and processed for cGMP immunocytochemistry. Anteriorly projecting neurons are labeled green, and NO-sensitive neurons are labeled red. A single cell (yellow) is double-labeled.

interneuron 1 (Int1), but its exact identity remains to be established.

\section{Gastric mill motor production requires NO diffusion and SGC activation}

We used in vitro preparations of the stomatogastric nervous system to study functional roles for $\mathrm{NO}-\mathrm{cGMP}$ signaling in the STG. The intact nervous system was pinned out on a Sylgardcoated dish, and a restriction well was constructed to isolate the STG from anterior ganglia (Fig. 6A). In this way, pharmacological agents could be bath-applied exclusively to the STG. The activity of identified STG neurons and the motor output from the ganglion were monitored using intracellular and extracellular recordings.

The in vitro STG spontaneously generates both a gastric mill and a pyloric motor rhythm (Fig. 6B). The two rhythms are distinct, and they can be distinguished by their periodicity. The gastric mill motor pattern (Fig. 6, top trace) is represented by the neurons that drive the medial tooth subsystem. Bursts of activity in gastric mill neurons (e.g., DG and GM) last for several seconds and have a period of 5-20 sec. By comparison, pyloric-timed activity (PD neurons, bottom trace) is rapid with a period of $\sim 1$ sec. In addition, some gastropyloric neurons such as VD and IC (middle trace) are influenced by both networks. Although the
STG produces the two rhythms in vitro, only the pyloric motor pattern is generated continuously. The gastric mill pattern is produced episodically and can suddenly stop or start. We used recordings from the medial tooth subsystem to monitor the presence or absence of gastric mill activity. We did not systematically record from the lateral tooth subsystem (LG and MG), and we did not monitor the variants of the gastric mill rhythm that involve the lateral tooth cells (Norris et al., 1994; Blitz et al., 1999).

The accumulation of citrulline within descending inputs to the STG suggests that NO is released within the ganglion under basal conditions when the two networks are conjointly active. Supplementation of the NO-cGMP pathway by bath application of NO donors ( $1 \mu \mathrm{M}$ to $1 \mathrm{mM} \mathrm{SNP}$ or SIN-1; $n=6)$ or 8-bromo-cGMP ( $1 \mathrm{mM} ; n=3$ ) had no significant effect on the basic structure of either motor rhythm (data not shown). By contrast, agents that interfere with endogenous NO-cGMP signaling had dramatic effects on both networks. We blocked the extracellular diffusion of NO within the ganglion using bath applications of PTIO, a specific NO scavenger (Akaike et al., 1993). Bath application of $250 \mu \mathrm{M}$ PTIO inhibited the gastric mill motor pattern (medial tooth subsystem) while leaving the pyloric pattern intact $(n=6$; Fig. 7). The gastric mill network was disassembled as the DG neuron fell silent, and the GM neurons began firing in phase with the pyloric rhythm. The IC and VD neurons, which were previously inhibited during part of the gastric cycle, now fired exclusively in pyloric time. When the STG was returned to normal saline, the gastric mill rhythm was reestablished within a few minutes. Therefore, by alternating PTIO treatment with normal saline, we could repeatedly disassemble and reassemble the gastric mill motor output from the ganglion.

We also examined the effects of removing endogenous cGMP production from the system by bathing the ganglion in $50 \mu \mathrm{M}$ ODQ ( $n=12$; Fig. $8 A$ ), a concentration sufficient to inhibit detectable NO-induced cGMP synthesis (Fig. $3 B$ ). The effects of ODQ were identical to those of PTIO, except that the changes in the gastric mill rhythm took place more rapidly $(<10 \mathrm{sec})$. Again, the DG neuron fell silent, and the GM, VD, and IC neurons began firing exclusively in pyloric time. As with PTIO treatments, the GM neurons switched between the gastric mill and pyloric motor networks when sGC activity was blocked (Fig. 8B). Finally, we examined the effect of ODQ on the LG neuron, which drives the protraction of the paired lateral teeth of the gastric mill (Heinzel et al., 1993). Similar to the GM neurons, this cell also switches to pyloric-timed activity in the presence of $50 \mu \mathrm{M}$ ODQ (Fig. $8 C ; n=3$ ). Therefore, the ODQ-induced respecification of the gastric mill network involves elements of both the lateral and medial tooth subsystems.

The modulatory effects of PTIO and ODQ treatments were not limited to neurons that normally participate in the gastric mill network. Both inhibitors also enhanced the pyloric rhythm. For example, ODQ significantly increased the pyloric cycle frequency, from $1.08 \pm 0.22 \mathrm{~Hz}$ in normal physiological saline to $1.58 \pm 0.38$ $\mathrm{Hz}$ in $50 \mu \mathrm{M}$ ODQ ( $p<0.001$; Student's $t$ test; $n=12)$. An example of the effect of ODQ on pyloric cycle frequency is shown in Figure $8 D$.

The results from ODQ treatments suggest that ongoing cGMP synthesis is necessary for the normal division of the in vitro STG into two functionally distinct and spontaneously active motor networks. To test whether exogenous applications of cGMP could rescue the effects of ODQ, we pretreated the STG for 10 min with $1 \mathrm{mM}$ 8-bromo-cGMP and then coapplied $1 \mathrm{mM}$ 8-bromo-cGMP and $50 \mu \mathrm{M}$ ODQ to the STG $(n=5)$. Surprisingly, ODQ contin- 


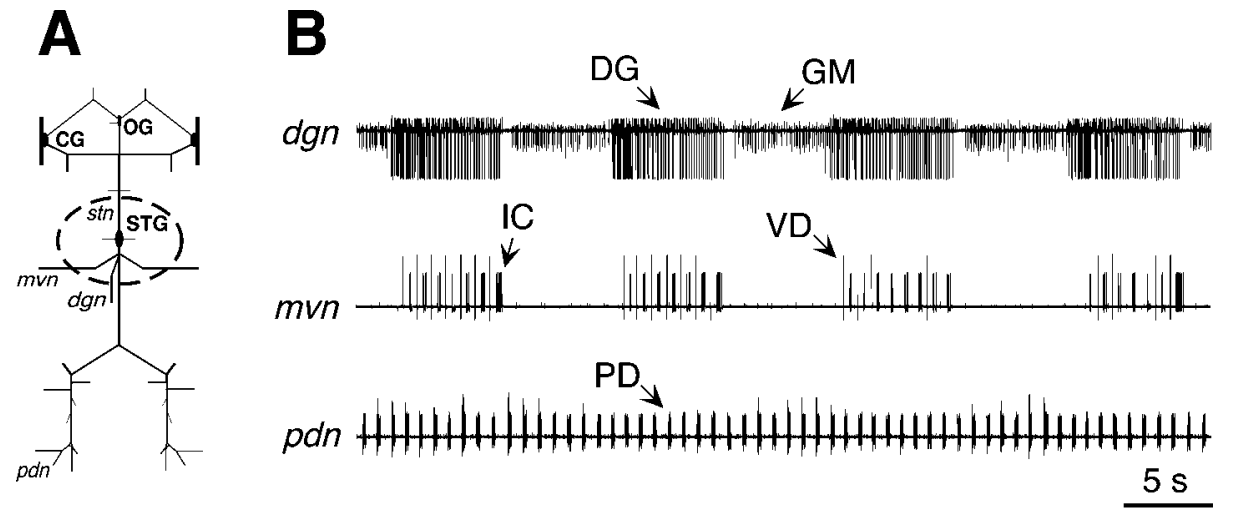

Figure 6. The STG generates a gastric mill and pyloric motor pattern in vitro. $A$, Schematic diagram of the isolated STNS. Anterior is up. Dashed line indicates the placement of a restriction well around the STG. $B$, Extracellular recordings from three nerves that carry output from the STG reveal distinct gastric mill and pyloric motor rhythms. The top trace shows the firing profiles of two gastric mill neurons $(D G$, $G M$ ), whereas the bottom trace shows the activity of a pyloric neuron $(P D)$. The middle trace shows the VD and IC neurons, which interact with both networks.

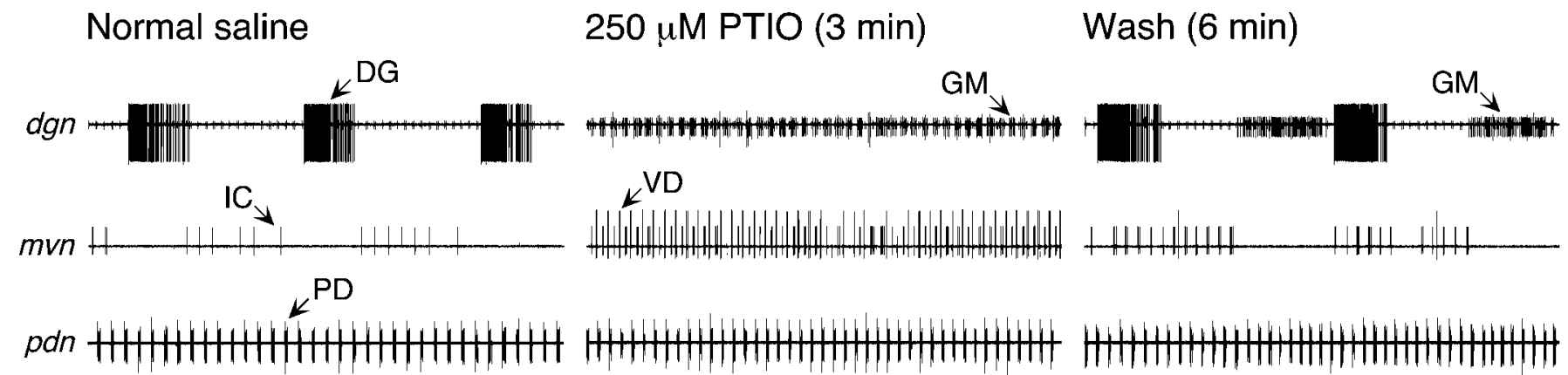

Figure 7. Pharmacological inhibition of NO diffusion selectively deconstructs the gastric mill motor rhythm. Extracellular recordings of motor output from the STG are shown. Note that the gastric mill rhythm in this preparation is less robust than in the experiment of Figure 6 (i.e., the GM neurons are not firing under basal conditions). Left, Both the gastric mill and the pyloric network are active in normal saline. Middle, Bath application of PTIO $(n=6)$, an extracellular NO scavenger, selectively shuts down the gastric mill rhythm (the DG neuron falls silent). The pyloric rhythm is excited, GM and VD neurons become active, and all active neurons now fire exclusively in pyloric time. Right, The effect of PTIO is reversible, and the gastric mill motor pattern returns when the STG is returned to normal saline.

ued to respecify the STG under these conditions (data not shown). Because the main glial sheath that surrounds the dorsal surface of the neuropil was removed in these experiments, stomatogastric neurons were directly exposed to the membranepermeant analog. Consequently, it is unlikely that 8-bromocGMP did not adequately penetrate into the synaptic neuropil. The cGMP analog may be ineffective in this preparation. Alternatively, the NO-cGMP pathway may normally act via cGMPregulated phosphodiesterases (PDEs), for which 8-bromo-cGMP has a low affinity (Lincoln and Cornwell, 1993).

Finally, NO-cGMP signaling appears to be necessary but not sufficient for gastric mill motor production. When descending neuromodulatory inputs to the ganglion are eliminated with a sucrose block to the stn and anterior ganglia, gastric mill-timed motor production ceases, and the pyloric pattern slows down or falls silent. Under these artificially suppressed conditions, bath applications of NO donors ( $1 \mu \mathrm{M}-1 \mathrm{~mm}$ SNP or SIN-1) do not elicit a gastric mill rhythm ( $n=5$; data not shown). The effects of NO-cGMP signaling are therefore activity-dependent, and they presumably require a coincident release of other neuromodulators within the STG.

\section{DISCUSSION}

We have shown that NO-cGMP neuromodulation contributes to the functional separation of the STG into two parallel motor networks. Moreover, under the conditions in which these experiments were conducted (i.e., spontaneous motor production from an in vitro preparation), the signaling pathway is required for the dynamic assembly of the circuit that drives the rhythmic chewing movements of the gastric mill. These results show that NO, acting via $\mathrm{sGC}$, can trigger rapid and reversible shifts in the specification of adult neural circuits (Fig. 9).

The PTIO data indicate that NO is diffusing within the STG when the pyloric and gastric motor rhythms are both spontaneously active. At least two NOS-like isoforms are expressed in the STNS, and one source of NO is likely to be the pair of descending inputs that terminate in the synaptic neuropil of the ganglion. In this respect, NO is similar to many other anterograde modulatory inputs that have been identified in this system (e.g., HarrisWarrick et al., 1992). Because citrulline accumulation was restricted to the distal axons and terminals of the NO-producing neurons, we were unable to identify their somata in anterior ganglia. It is therefore unclear whether NO is released as a cotransmitter, as has been demonstrated in Aplysia (Jacklet, 1995), or whether the NOS-containing neurons are coactivated with parallel descending inputs to the STG. NO may also be released from another source (e.g., a single neuron within the ganglion itself).

The STG neurons that contain a NO-sensitive sGC include the core neurons of the pyloric circuit (PD, PY, and LP) as well as the four GM neurons that can switch between the gastric mill and pyloric networks. An interneuron with an ascending axon (either $\mathrm{AB}$ or Int1) is likely to be the last member of the NO-responsive 


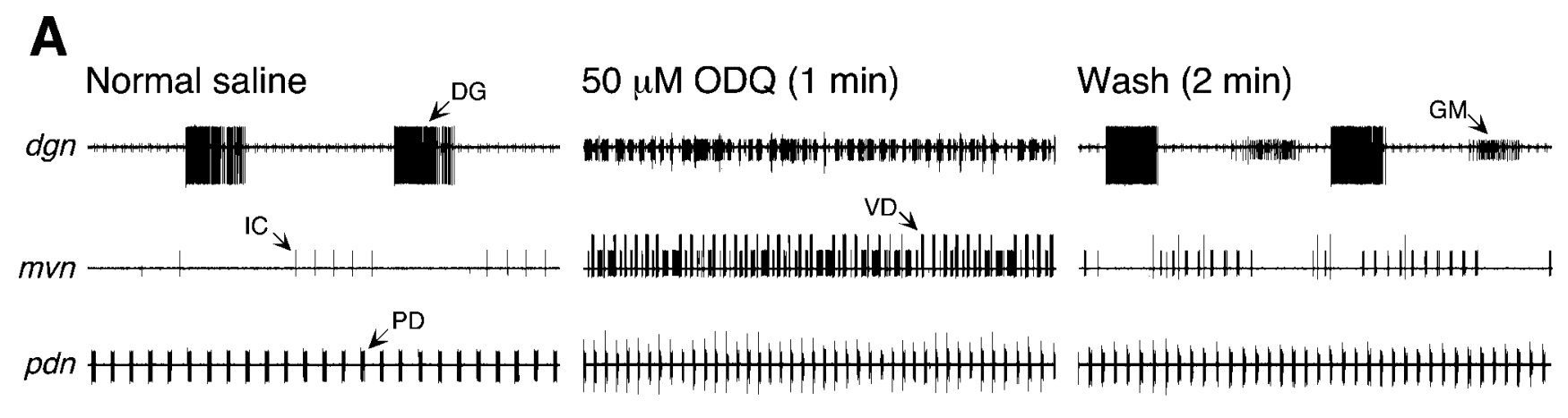

B

Normal saline

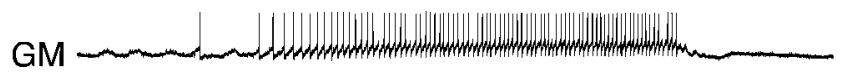

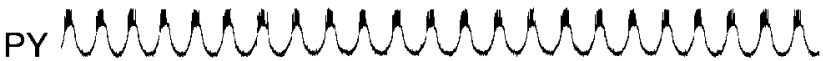

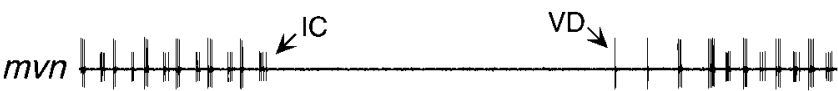

$50 \mu \mathrm{M} \mathrm{ODQ}$

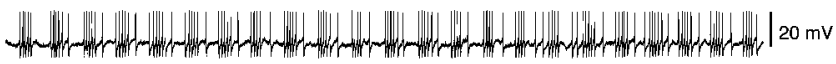

Munculumuman

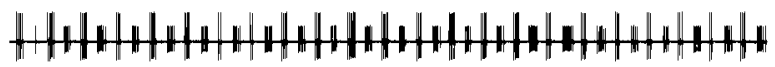

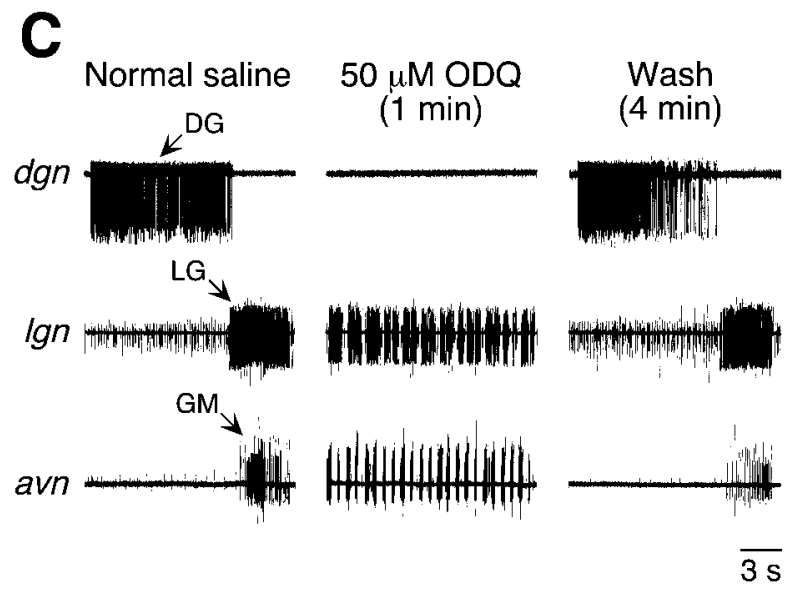

D

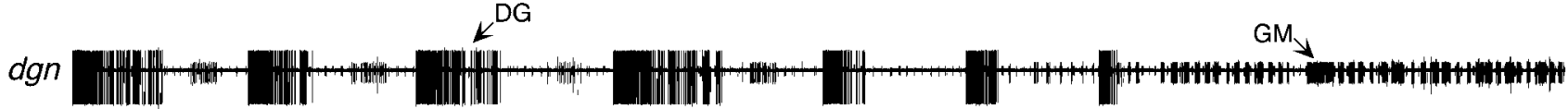

$p d n \mathrm{HHH}+\mathrm{HHH}+\mathrm{K}+\mathrm{H}$

Figure 8. Bath applications of ODQ $(n=12)$, an inhibitor of NO-sensitive sGC, triggers a rapid and reversible disassembly of the gastric mill motor rhythm. $A$, As with PTIO (Fig. 7), ODQ inhibits the gastric mill rhythm and excites the pyloric rhythm. $B$, STG neurons pattern switch when NO-sensitive sGC activity is blocked within the ganglion. Shown are paired intracellular recordings from a GM and PY neuron, and an extracellular recording of the IC and VD neurons (bottom trace). In normal saline (left), the GM neuron fires in gastric time (a single burst in a gastric cycle is shown here), and the PY neuron fires in pyloric time. The IC and VD neurons fire in pyloric time but are inhibited during the GM burst. Within seconds of ODQ application (right), the GM cells pattern switch and begin firing in pyloric time. Note that the IC and VD neurons now participate exclusively in the pyloric motor pattern. Most hyperpolarized membrane potentials: $\mathrm{GM},-54 \mathrm{mV}$; PY, $-59 \mathrm{mV}$. C, ODQ-induced pattern switching is not limited to medial tooth neurons in the gastric mill network. Extracellular recordings from the lateral gastric nerve (lgn, middle trace) reveal that LG, which drives the protraction of the paired lateral teeth, also switches to pyloric-timed activity when NO-cGMP signaling is blocked within the ganglion $(n=3)$. $D$, Time course for ODQ-induced disassembly of the gastric mill rhythm (top trace). Note also the increase in the pyloric cycle frequency and the occasional summation of PD units in the pdn (bottom trace). 


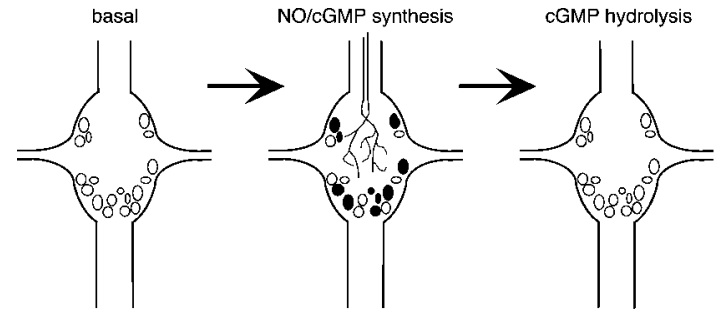

म11010

$\mathrm{H} \mathrm{H} \mathrm{H} H \mathrm{H} H \mathrm{H}$

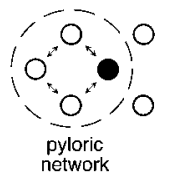

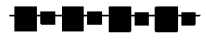

$\mathrm{H} H \mathrm{H} H \mathrm{HH} H$

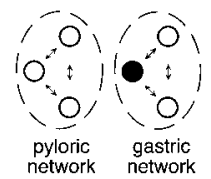

H+1+1+1+1

HHHHHHH

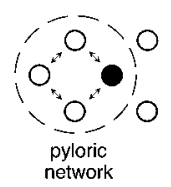

Figure 9. A proposed role for NO-cGMP neuromodulation in the rapid and reversible partitioning of STG motor networks. This model assumes that NO-cGMP signaling interacts with parallel modulatory inputs (data not shown), which are intact and active. Left, Between bouts of feeding, NO-cGMP neuromodulation is absent. The pyloric network is active, and gastric mill units are either silent (open circles) or participate in the pyloric rhythm ( filled circle). Middle, When food reaches the gastric mill, $\mathrm{NO}$ is released into the STG neuropil from descending inputs or another as yet unidentified source. cGMP accumulates in a subset of neurons, and motor output from the ganglion is partitioned into two parallel rhythms. Previously silent gastric mill neurons become active, whereas others pattern switch from the pyloric network to the gastric mill network ( filled circle). Right, NO release stops when food is no longer present in the foregut. cGMP is rapidly hydrolyzed, and the STG returns to a unitary network configuration.

group. Suppression of intrinsic NO-cGMP signaling, using either ODQ or PTIO, speeds up the core pyloric rhythm and causes the GM neurons to pattern switch and burst in pyloric time. Therefore, in the context of the 12 identified sGC-expressing cells, the suppression of the NO pathway results in a ganglion that is dominated by the pyloric motor rhythm. It is important to stress, however, that PTIO- and ODQ-induced changes in firing activity are not limited to neurons that express the receptor of NO. For example, the activity of NO-insensitive neurons (e.g., DG, VD, and IC) also changes when NO-cGMP signaling is inhibited. These indirect effects of NO are likely to reflect synaptic interactions between NO-sensitive and NO-insensitive cells. The nature of these interactions has yet to be determined.

NO donors were not sufficient to activate gastric mill motor output from the STG when descending inputs were blocked. This suggests that NO-cGMP may need to interact with other intracellular signaling pathways that are active in the intact system (Bhalla and Iyengar, 1999). Stomatogastric neurons must integrate modulatory input from a wide array of transmitters and circulating neurohormones, and cross talk between second messenger cascades is likely to determine the cellular and synaptic properties of individual STG neurons. Moreover, it may not be possible to relate a transmitter-evoked second messenger cascade to effects at the level of the circuit without an understanding of how that cascade interacts with other, parallel pathways in cells. For example, Hempel et al. (1996) found that serotonin, dopamine, and octopamine evoke different patterns of cAMP synthesis among STG neurons. However, the modulatory effects of each transmitter at the level of the network could not be explained by the cell-specific patterns of cAMP accumulation within the ganglion. Biochemical interactions between different signaling path- ways have not been studied in the STG, and this remains an important area for future research.

One possible mechanism for interactions between cGMP and parallel biochemical cascades in the STG could involve the activation of cGMP-regulated phosphodiesterases (e.g., PDE3; Delpy et al., 1996; Lugnier et al., 1999; Sandner et al., 1999). These enzymes hydrolyze cAMP and provide an important mechanism for cross talk between cGMP- and cAMP-mediated signaling cascades (Lincoln and Cornwell, 1993; Pelligrino and Wang, 1998). For example, the NO-cGMP signaling pathway could function to regulate intracellular cAMP, and therefore serve as a "gain control" for parallel inputs (e.g., the biogenic amines) that activate adenylate cyclase. This would be consistent with our observation that NO is not sufficient to evoke motor activity in the absence of descending inputs to the ganglion.

Finally, NO-cGMP signaling is also closely associated with the gastric mill rhythm during STG development. In lobsters, the teeth of the gastric mill and the underlying gastric mill motor pattern first appear at metamorphosis (Casasnovas and Meyrand, 1995). A single STG neuron begins to express sGC at this stage (Scholz et al., 1998). As the gastric mill rhythm matures during early juvenile development, additional neurons become NOresponsive. Several transmitter inputs to the STG also mature in the stages leading up to metamorphosis (Fénelon et al., 1999; Kilman et al., 1999), and NO may interact with these pathways to shape the gradual emergence of adult-specific behaviors.

\section{REFERENCES}

Akaike T, Yoshida M, Miyamoto Y, Sato K, Kohno M, Sasamoto K, Miyazaki K, Ueda S, Maeda H (1993) Antagonistic action of imidazolineoxyl $N$-oxides against endothelium-derived relaxing factor/.NO through a radical reaction. Biochemistry 32:827-832.

Baldwin DH, Graubard K (1995) Distributions of fine neurites of stomatogastric neurons of the crab Cancer borealis: evidence for a structured neuropil. J Comp Neurol 356:355-367.

Bartos M, Nusbaum MP (1997) Intercircuit control of motor pattern modulation by presynaptic inhibition. J Neurosci 17:2247-2256.

Bartos M, Manor Y, Nadim F, Marder E, Nusbaum MP (1999) Coordination of fast and slow rhythmic neuronal networks. J Neurosci 19:6650-6660.

Bhalla US, Iyengar R (1999) Emergent properties of networks of biological signaling pathways. Science 283:381-387.

Blitz DM, Christie AE, Coleman MJ, Norris BJ, Marder E, Nusbaum MP (1999) Different proctolin neurons elicit distinct motor patterns from a multifunctional neuronal network. J Neurosci 19:5449-5463.

Bredt DS, Snyder SH (1990) Isolation of nitric oxide synthetase, a calmodulin-requiring enzyme. Proc Natl Acad Sci USA 87:682-685.

Casasnovas B, Meyrand P (1995) Functional differentiation of adult neural circuits from a single embryonic network. J Neurosci 15:5703-5718.

Coleman MJ, Nusbaum MP (1994) Functional consequences of compartmentalization of synaptic input. J Neurosci 14:6544-6552.

Delpy E, Coste H, Gouville AC (1996) Effects of cyclic GMP elevation on isoprenaline-induced increase in cyclic AMP and relaxation in rat aortic smooth muscle: role of phosphodiesterase 3 . Br J Pharmacol 119:471-478.

Denninger JW, Marletta MA (1999) Guanylate cyclase and the NO/ cGMP signaling pathway. Biochim Biophys Acta 1411:334-350.

de Vente J, Steinbusch HW (1997) cGMP-immunocytochemistry. Methods Mol Biol 72:125-143.

Dickinson PS, Nagy F, Moulins M (1988) Control of central pattern generators by an identified neurone in crustacea: activation of the gastric mill motor pattern by a neurone known to modulate the pyloric network. J Exp Biol 136:53-87.

Eliasson MJL, Blackshaw S, Schell MJ, Snyder SH (1997) Neuronal nitric oxide synthase alternatively spliced forms: prominent functional localizations in the brain. Proc Natl Acad Sci USA 94:3396-3401.

Elphick MR, Kemenes G, Staras K, O'Shea M (1995) Behavioral role for nitric oxide in chemosensory activation of feeding in a mollusc. J Neurosci 15:7653-7664.

Fénelon VS, Kilman V, Meyrand P, Marder E (1999) Sequential developmental acquisition of neuromodulatory inputs to a central patterngenerating network. J Comp Neurol 408:335-351.

Gally JA, Montague PR, Reeke GN, Edelman GM (1990) The NO hypothesis: possible effects of a short-lived, rapidly diffusible signal in 
the development and function of the nervous system. Proc Natl Acad Sci USA 87:3547-3551.

Garthwaite J, Boulton CL (1995) Nitric oxide signaling in the central nervous system. Annu Rev Physiol 57:683-706.

Garthwaite J, Southam E, Boulton CL, Nielsen EB, Schmidt K, Mayer B (1995) Potent and selective inhibition of nitric oxide-sensitive guanylyl cyclase by $1 \mathrm{H}-(1,2,4)$ oxadiazolo(4,3-a)-quinoxalin-1-one. Mol Pharmacol 48:184-188.

Gelperin A, Flores J, Raccuia-Behling F, Cooke IR (2000) Nitric oxide and carbon monoxide modulate oscillations of olfactory interneurons in a terrestrial mollusk. J Neurophysiol 83:116-127.

Gibbs SM, Truman JW (1998) Nitric oxide and cyclic GMP regulate retinal patterning in the optic lobe of Drosophila. Neuron 20:83-93.

Harris-Warrick RM, Nagy F, Nusbaum MP (1992) Neuromodulation of stomatogastric networks by identified neurons and transmitters. In: Dynamic biological networks: the stomatogastric nervous system (Harris-Warrick RM, Marder E, Selverston A, Moulins M, eds), pp. 87-138. Cambridge, MA: MIT.

Harris-Warrick RM, Baro DJ, Coniglio LM, Johnson BR, Levini RM, Peck JH, Zhang B (1997) Chemical modulation of crustacean stomatogastric pattern generator networks. In: Neurons, networks, and motor behavior (Stein PG, Grillner S, Selverston AI, Stuart DG, eds), pp 209-215. Cambridge, MA: MIT.

Hedrick MS, Morales RD (1999) Nitric oxide as a modulator of central respiratory rhythm in the isolated brainstem of the bullfrog (Rana catesbeiana). Comp Biochem Physiol A Mol Integr Physiol 124:243-251.

Heinzel HG, Selverston AI (1988) Gastric mill activity in the lobster. III. The effects of proctolin on the isolated central pattern generator. J Neurophysiol 59:566-585.

Heinzel HG, Weimann JW, Marder E (1993) The behavioral repertoire of the gastric mill in the crab Cancer pagurus: an in situ endoscopic and electrophysiological examination. J Neurosci 13:1793-1803.

Hempel CM, Vincent P, Adams SR, Tsien RY, Selverston AI (1996) Spatio-temporal dynamics of cAMP signals in an intact neural circuit. Nature 384:166-169.

Jacklet JW (1995) Nitric oxide is used as an orthograde cotransmitter at identified histaminergic synapses. J Neurophysiol 74:891-895.

Jacklet JW (1997) Nitric oxide signaling in invertebrates. Invert Neurosci 3:1-14.

Johansson KUI, Carlberg M (1994) NADPH-diaphorase histochemistry and nitric oxide synthase activity in deutocerebrum of the crayfish, Pacifastacus leniusculus (crustacea, decapoda). Brain Res 649:36-42.

Katz P, Harris-Warrick RM (1991) Recruitment of crab gastric mill neurons into the pyloric motor pattern by mechanosensory afferent stimulation. J Neurophysiol 65:1442-1451.

Katz PS, Harris-Warrick RM (1989) Serotonergic/cholinergic muscle receptor cells in the crab stomatogastric nervous system. II. Rapid nicotinic and prolonged modulatory effects on neurons in the stomatogastric ganglion. J Neurophysiol 62:571-581.

Kilman V, Fénelon VS, Richards KS, Thirumalai V, Meyrand P, Marder E (1999) Sequential developmental acquisition of cotransmitters in identified sensory neurons of the stomatogastric nervous system of the lobsters, Homarus americanus and Homarus gammarus. J Comp Neurol 408:318-334.

Lincoln TM, Cornwell TL (1993) Intracellular cyclic GMP receptor proteins. FASEB J 7:328-338.

Lugnier C, Keravis T, Eckly-Michel A (1999) Cross talk between NO and cyclic nucleotide phosphodiesterases in the modulation of signal transduction in blood vessel. J Physiol Pharmacol 50:639-652.
Marder E, Hooper SL, Siwicki KK (1986) Modulatory action and distribution of the neuropeptide proctolin in the crustacean stomatogastric nervous system. J Comp Neurol 243:454-467.

Marder E, Skiebe P, Christie AE (1994) Multiple modes of network modulation. Verh Dtsch Zool Ges 87:177-184.

McLean DL, Sillar KT (2000) The distribution of NADPH-diaphoraselabelled interneurons and the role of nitric oxide in the swimming system of Xenopus laevis larvae. J Exp Biol 203:705-713.

Mulloney B, Selverston AI (1974) Organization of the stomatogastric ganglion in the spiny lobster. I. Neurons driving the lateral teeth. J Comp Physiol 91:1-32.

Nadim F, Manor Y, Nusbaum M, Marder E (1998) Frequency regulation of a slow rhythm by a fast periodic input. J Neurosci 18:5053-5067.

Norris BJ, Coleman MJ, Nusbaum MP (1994) Recruitment of a projection neuron determines gastric mill motor pattern selection in the stomatogastric nervous system of the crab, Cancer borealis. J Neurophysiol 72:1451-1463.

Pape HC, Mager R (1992) Nitric oxide controls oscillatory activity in thalamocortical neurons. Neuron 9:441-448.

Pelligrino DA, Wang Q (1998) Cyclic nucleotide cross talk and the regulation of cerebral vasodilation. Prog Neurobiol 56:1-18.

Sandner P, Kornfeld M, Ruan X, Arendshorst WJ, Kurtz A (1999) Nitric oxide/cAMP interactions in the control of rat renal vascular resistance. Circ Res 84:186-192.

Scholz NL, Truman JW (2000) Invertebrate models for studying NOmediated signaling. In: Handbook of chemical neuroanatomy, Vol 17, Functional neuroanatomy of the nitric oxide system (Steinbusch HWM, De Vente J, Vincent SR, Bjorklund A, Hokfelt T, eds), pp 417-441. Amsterdam, The Netherlands: Elsevier Science.

Scholz NL, Goy MF, Truman JW, Graubard K (1996) Nitric oxide and peptide neurohormones activate cGMP synthesis in the crab stomatogastric nervous system. J Neurosci 16:1614-1622.

Scholz NL, Chang ES, Graubard K, Truman JW (1998) The NO/cGMP signaling pathway and the development of neural networks in postembryonic lobsters. J Neurobiol 34:208-226.

Truman JW, de Vente J, Ball EE (1996) Nitric oxide-sensitive guanylate cyclase activity is associated with the maturational phase of neuronal development in insects. Development 122:3949-3958.

Turrigiano GG, Selverston AI (1990) A cholecystokinin-like hormone activates a feeding-related neural circuit in lobster. Nature 344:866-868

Weimann JM, Marder E (1994) Switching neurons are integral members of multiple oscillatory networks. Curr Biol 4:896-902.

Weimann JM, Meyrand P, Marder E (1991) Neurons that form multiple pattern generators: identification and multiple activity patterns of gastric/pyloric neurons in the crab stomatogastric system. J Neurophysiol 65:111-122.

Weimann JM, Marder E, Evans B, Calabrese RL (1993) The effects of SDRNFLRFamide and TNRNFLRFamide on the motor patterns of the stomatogastric ganglion of the crab Cancer borealis. J Exp Biol 181:1-26.

Weimann JM, Skiebe P, Heinzel H-G, Soto C, Kopell N, Jorge-Rivera JC, Marder E (1997) Modulation of oscillator interactions in the crab stomatogastric ganglion by crustacean cardioactive peptide. J Neurosci 17:1748-1760.

Zhao Y, Brandish PE, Ballou DP, Marletta MA (1999) A molecular basis for nitric oxide sensing by soluble guanylate cyclase. Proc Natl Acad Sci USA 96:14753-14758. 